\title{
Research on Quantitative Calculation Model of Social Benefits of Power Grid Investment Based on Input Output Table
}

\author{
Jianqing $\mathrm{Li}^{1}{ }^{1}{ }^{*}$, Wei Xie ${ }^{2}$, Haihong $\mathrm{Du}^{2}$, Wenming Pan ${ }^{2}$, Xiaohu Zhu ${ }^{1}$, and Yidi Wan ${ }^{1}$ \\ ${ }^{1}$ State Grid Anhui Economic Research Institute, Hefei, Anhui, China \\ ${ }^{2}$ State Grid Anhui Electric Power Co., Ltd, Hefei Anhui, China
}

\begin{abstract}
Under the strategic goal of "an international leading energy Internet enterprise with Chinese characteristics", in the face of severe domestic and international economic situation, power grid companies actively fulfill their social responsibilities and invest in key industrial chains. Based on the input-output method, using the latest input-output data of 42 industries, this paper constructs the quantitative relationship between investment and GDP increment, investment and employment added value, and carries out quantitative analysis on the pulling effect of investment on the economy of various industries and the role of employment growth, so as to provide quantitative reference for power grid investment decision-making and social responsibility performance.
\end{abstract}

\section{Research background}

2020 is the decisive year for building a moderately prosperous society in all respects, a key year to achieve the first centenary goal, and the last year of the 13th fiveyear plan. Affected by the epidemic situation and the low economic growth at home and abroad, the operation situation of power grid companies is extremely grim. Under the strategic goal of "an international leading energy Internet enterprise with Chinese characteristics", the power grid company has actively fulfilled the social responsibility of state-owned enterprises, coordinated the work of epidemic prevention and control and economic and social development, unswervingly implemented the new development concept, strengthened the factor guarantee around the key industrial chain, leading enterprises and major investment projects, promoted the coordination of upstream and downstream, production, supply and marketing, large and medium-sized enterprises, and accelerated the high-quality development of strategic emerging industries. It is an important force in the service construction of a new development pattern of "taking the domestic big cycle as the main body and promoting the domestic and international double circulation mutually".

Based on the input-output table, using the latest input-output data of 42 industries, this paper constructs the quantitative relationship between investment and GDP increment, investment and employment added value under the principle of "total input = total output", carries out quantitative analysis on the pulling effect of investment on the economy of various industries, and comprehensively considers the average wage level of each industry to quantify the pulling effect of investment on employment of various industries Network investment decision-making and social responsibility performance to provide quantitative reference.

\section{Research method}

Based on the input-output method, the quantitative analysis of the impact of investment on economy and society is carried out. The input-output table is a kind of checkerboard table which reflects the sources and distribution directions of production inputs of various products. The input-output method is an economic quantitative analysis method that systematically analyses the quantitative dependence among various sectors of the national economy and various links of reproduction by constructing the input-output table. Among them, input refers to all kinds of consumption in an economic activity, including the consumption of tangible (material) products and intangible (non-material) products; output refers to the results of production activities and distribution, including material and non-material products, physical and service products.

\subsection{Quantitative method of investment economic impact}

\subsubsection{Basic structure of input output table}

\footnotetext{
* Corresponding author: Jianqing Li (283093599@qq.com)
} 


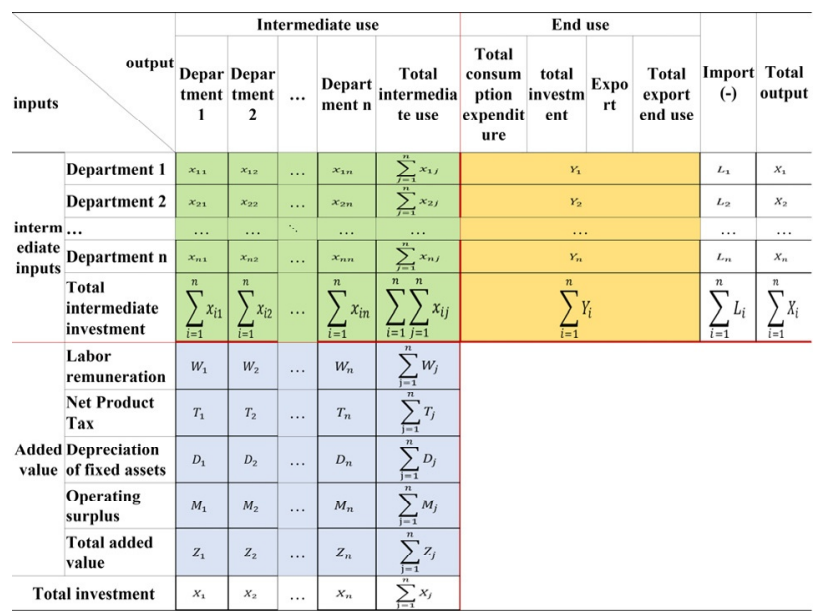

Fig. 1. Input output table.

The input-output table is divided into four quadrants: the first quadrant is the intermediate input index; the second quadrant is the final consumption product; the third quadrant is the added value; the fourth quadrant is the income distribution relationship. Among them, the first quadrant and the second quadrant are the output; the first and the third quadrant are the input; based on the "total input = total output" relationship, the correlation between the investment amount in the second quadrant and the GDP increment in the third quadrant is quantified.

In the first quadrant: $x i j, i$ is the row number and $\mathrm{j}$ is the column number. From the vertical column, the quantity of $\mathrm{i}$ product consumed in the production of department $\mathrm{j}$ in the table, and from the horizontal row, the quantity of product $i$ in the table allocated to department $\mathrm{j}$ for production.

In the second quadrant: $\mathrm{Yi}, \mathrm{i}$ is the line number. $\mathrm{Yi}$ represents the number of products of department $i$ used for final use.

In the third quadrant: $\mathrm{Zj}=\mathrm{Wj}+\mathrm{Tj}+\mathrm{Dj}+\mathrm{Mj}, \quad \mathrm{Zj}$ Represents the value added of sector $\mathrm{j}$ in the reporting period, i.e. the value corresponding to GDP, $\mathrm{Wj}, \mathrm{Tj}, \mathrm{Dj}$, $\mathrm{Mj}$ correspond to the labor remuneration, production tax, depreciation of fixed assets and operating surplus of department $\mathrm{j}$ respectively.

Row relationship: intermediate use + final product $=$ total output

Determinant relationship: intermediate input + added value $=$ total input

Total balance: total input $=$ total output.

\subsubsection{Relationship building}

Based on "total input = total output", the calculation of correlation coefficient mainly includes direct consumption coefficient, complete consumption coefficient, direct distribution coefficient, complete distribution coefficient and added value coefficient.

(1) Direct consumption coefficient is the direct input coefficient, also known as the direct demand coefficient or technical coefficient. It is the consumption of one product to another.

$$
a i j=x i j / x i
$$

The meaning of aij is the value consumption of product $i$ in each unit of total output of department $j$. The direct consumption coefficient of a department is expressed in the form of table, which is $\mathrm{n} \times \mathrm{n}$ direct consumption coefficient matrix, which is usually represented by the letter $\mathrm{A}$.

$$
A=\left[\begin{array}{cccc}
a_{11} & a_{12} & \cdots & a_{1 n} \\
a_{21} & a_{22} & \cdots & a_{2 n} \\
\vdots & \vdots & \vdots & \vdots \\
a_{n 1} & a_{n 1} & \cdots & a_{n n}
\end{array}\right]
$$

Through the direct consumption coefficient, we can establish the relationship model between the final product and the total output.

$$
\sum_{j=1}^{n} a_{i j} X_{i j}+Y_{i}=X_{i}(i=1,2, \cdots, n)
$$

The final product quantity is expressed as $\mathrm{Xi}$ and $\mathrm{Yi}$, respectively.

$$
\begin{aligned}
& X=\left(\begin{array}{llll}
X 1 & X 2 & \ldots & X n
\end{array}\right) T \\
& Y=\left(\begin{array}{llll}
Y 1 & Y 2 & \cdots & Y n
\end{array}\right) T
\end{aligned}
$$

In the form of matrix, it can be expressed as follows:

$$
A \cdot X+Y=X \rightarrow X=(I-A)-1 \cdot Y
$$

(2) The coefficient of complete consumption refers to the total consumption of goods or services in sector $i$ for each unit value of final product produced by department $\mathrm{j}$, which is recorded as Bij. The calculation formula is as follows:

$$
b_{i j}=a_{i j}+\sum_{k=1}^{n} b_{i k} a_{k j}
$$

The above formula is expressed in the form of matrix:

$$
B=A+B \cdot A \rightarrow B=(I-A)-1-1
$$

There is only 1 difference in diagonal elements between Leontiev inverse matrix and complete consumption coefficient.

(3) The direct distribution coefficient is the ratio of the quantity allocated by a product department to a consuming department and the total output of the Department. It includes the distribution coefficient of intermediate products and the distribution coefficient of final products.

$$
C i j=X i j / x i
$$

Cij means the proportion of $\mathrm{i}$ product allocated by department $\mathrm{j}$.

(4) The coefficient of complete distribution is the total amount allocated by a product department to a consuming department or an end use, which is recorded as Dij. Complete distribution coefficient matrix:

$$
D=(I-C)-1-1
$$


It reflects the complete pushing effect of complete $\mathrm{i}$ sector on $\mathrm{j}$ sector.

(5) If the sum of labor remuneration, net production tax, depreciation of fixed assets and operating surplus is the added value, then the added value coefficient is:

$$
a_{z j}=a_{w j}+a_{i j}+a_{d j}+a_{m j}=\frac{W_{j}}{X_{j}}+\frac{T_{j}}{X_{j}}+\frac{D_{j}}{X_{j}}+\frac{M_{j}}{X_{j}}=\frac{Z_{j}}{X_{j}}
$$

\subsubsection{Construction of quantitative model of investment economic impact}

Build a partial closed input-output model to quantify the economic impact of investment. In the basic input-output model $\mathrm{X}=(\mathrm{I}-\mathrm{A})-1$, the final demand, intermediate use and final use are distinguished, and the final demand (including consumption, investment and export) is regarded as exogenous variable. Thus, the change of final demand $(\mathrm{Y})$ will bring about the change of output (X) under the condition of constant technical coefficient. In the input-output analysis model, some variables are regarded as exogenous variables, which is called inputoutput open model. If all the final demand $(\mathrm{Y})$ is included in the intermediate flow matrix, then an expanded coefficient matrix $A^{*}$ is obtained when $\mathrm{y}=0$, and the row to row equilibrium relationship is transformed from $\mathrm{AX}+\mathrm{Y}=\mathrm{X}$ to $\mathrm{A}^{*} \cdot \mathrm{X}^{*}=\mathrm{X}^{*}$. At this time, all variables in the model are endogenous, which is called input-output closed model.

In order to meet the needs of analysis, the inputoutput research proposed to put a part of the final demand (Y) into the intermediate flow plus endogenous. In this study, the input-output partial closed model is used for relevant calculation, that is, residents are also included in the intermediate flow matrix as a sector, which not only takes into account the direct pulling effect of investment on production, but also takes into account the indirect pull effect brought by the increase of residents' income and the expansion of consumption capacity. The direct consumption coefficient of the partially closed model can be expressed as follows:

$$
A^{*}=\left[\begin{array}{cccc}
a_{11} & a_{12} & \cdots & a_{1 n+1} \\
a_{21} & a_{22} & \cdots & a_{2 n+1} \\
\vdots & \vdots & \vdots & \vdots \\
a_{n+1,1} & a_{n+1,1} & \cdots & a_{n+1, n+1}
\end{array}\right]=\left[\begin{array}{cc}
A & H_{C} \\
H_{r} & h
\end{array}\right]
$$

Among them, $\mathrm{Hr}$ is the row vector of labor remuneration coefficient of each department, Hc is the direct consumption coefficient series vector of products and services of various departments by residents, and $h$ is the payment coefficient of resident department to resident department.

From the input-output basic line model, it can be concluded that in the local closed model, there are:

$$
\Delta X=\left(I-A^{*}\right)-1 \Delta Y
$$

$$
\Delta G D P=A Z \cdot \Delta X=A Z \cdot\left(I-A^{*}\right)-1 \Delta Y
$$

Where $\Delta \mathrm{Y}$ is the investment vector, $\mathrm{AZ}$ is the added value coefficient diagonal matrix, and the elements on the diagonal are the added value coefficients of each sector.

\subsection{Quantitative method of social impact of investment}

Take the pulling effect of investment on social employment as the social benefit of investment.

\subsubsection{Construction of employment effect index}

The employment effect index belongs to social and environmental parameter index, which can be expressed by unit investment employment effect, direct employment effect and indirect employment effect. The employment effect index reflects the number of people employed per 10000 yuan of investment. The specific calculation method is as follows:

The total employment effect is the total employment effect (including direct employment and indirect employment) brought by investment to the society:

Total employment benefit $=($ new total employment number (person)) / (total construction investment (10000 yuan)). Among them: total employment $=$ direct employment + indirect employment; total construction investment $=$ direct investment + indirect investment.

Direct employment effect refers to the employment effect directly brought by investment. Direct employment benefit $=$ (number of people directly employed) / (direct construction investment (10000 yuan))

Indirect employment effect refers to the number of indirect employments created by additional investment in supporting services or related projects related to direct investment.

Indirect employment benefit $=$ (indirect employment number (person)) / (indirect investment of relevant departments (10000 yuan)).

\subsubsection{The construction of employment contribution model}

The direct employment contribution is the ratio of the total remuneration obtained by the workers in the industrial sector to the total input, namely DL. Among them, $\mathrm{Wj}$ is the total remuneration obtained by the workers in the $\mathrm{j}$ sector, and $\mathrm{Xj}$ is the total input of the $\mathrm{j}$ sector. Indirect employment contribution is the input of one sector, which indirectly drives the development of other industrial sectors, thus bringing certain employment opportunities to other sectors. The sum of direct employment contribution and indirect employment contribution is equal to full employment contribution. Namely:

$$
G L_{1}=D L_{1}+I L_{j}=D L_{+}+\sum_{j=1}^{n}\left(G L_{,}-a_{i j}\right)=\left(I-A^{*}\right)^{-1} \cdot D L_{1}
$$


Where GLj is the contribution to full employment and $\mathrm{ILj}$ is the indirect contribution to employment in sector $\mathrm{j}$.

The pull of investment on employment refers to that investment directly or indirectly drives the development of relevant industrial sectors, thus increasing the labor demand of relevant industrial sectors, and then stimulating employment. Employment pull includes direct employment pull and indirect employment pull, the specific analysis is as follows:

Direct employment pull means that investment drives the development of directly related industrial sectors, thus increasing the number of employments. The calculation model of direct employment pull is as follows:

$$
L=\frac{\Delta Y \cdot D L_{\mathrm{j}}}{S_{\mathrm{i}}}(i=1,2, \cdots, n)
$$

Where: $\mathrm{L}$ is the annual average number of jobs directly driven by department $\mathrm{j}$, and $\mathrm{Si}$ number is the annual average wage level of department $j$.

Indirect employment pull refers to that the investment in relevant industrial sectors indirectly drives the development of other industrial sectors (except the industrial sector), so as to increase the employment of these industrial sectors.

$$
L^{\prime}=\frac{\Delta Y \cdot D L_{j}}{\bar{S}}(i=1,2, \cdots, n)
$$

Where: $\mathrm{L}$ is the annual average number of jobs indirectly driven by the $\mathrm{j}$ sector, and is the average wage level of all industrial sectors.

According to the calculation model of direct and indirect employment pull, the calculation of direct and indirect employment brought by grid investment is carried out, so as to quantify the social benefits of power grid investment.

\section{Model demonstration}

Under the severe international trade situation, the state has put forward a new development pattern of "taking the domestic big cycle as the main body and promoting the domestic and international double circulation mutually". As one of the "troikas" of economic development, it is particularly important to play the role of investment in promoting the economy. Therefore, a unit plans to invest 13.525 billion yuan in infrastructure construction of power grid, and calculate the economic and social benefits generated by the investment scale.

\subsection{Economic benefit analysis of power grid investment}

On the basis of transforming the fixed assets investment of power grid into the demand for relevant investment products production departments, the GDP increment value and employment added value under the demand amount of various industries are calculated based on the input-output method, and the economic and social impact analysis of power grid investment is carried out.

\subsubsection{Breakdown of power grid investment details}

Taking 13.525 billion yuan of grid infrastructure investment of a unit as an example, the classified investment scale is calculated through the typical proportion of various costs.

Table 1. Detailed investment scale of power grid by cost.

\begin{tabular}{|c|c|c|c|}
\hline Cost(billion) & $\begin{array}{c}\text { Construction and } \\
\text { installation cost }\end{array}$ & $\begin{array}{c}\text { Equipment } \\
\text { purchase cost }\end{array}$ & other \\
\hline Proportion & $37 \%$ & $48 \%$ & $16 \%$ \\
\hline $\begin{array}{c}\text { Scale of } \\
\text { dismantling } \\
\text { investment }\end{array}$ & 5.004 & 6.424 & 2.096 \\
\hline
\end{tabular}

\subsubsection{Calculation of demand of power grid investment to production department}

Calculation of the demand of power grid investment on the production sector, power grid infrastructure investment mainly includes construction and installation costs, equipment purchases costs and other costs. Among them, the construction and installation engineering cost corresponds to the construction industry in the inputoutput table; the equipment purchase cost corresponds to the metal products, electrical machinery and equipment, communication equipment, computer and other electronic equipment industry in the input-output table; other expenses generally include consulting fee, design fee and management fee, which correspond to the scientific research and technical service in the inputoutput table. According to the corresponding relationship between the costs and the input-output table, the amount of investment that plays a driving role in the economy is 11.557 billion yuan.

\subsubsection{Calculation of new output of various industries driven by power grid investment}

The direct consumption coefficient $A^{*}$ is calculated based on the input-output table, and the Leontiev inverse matrix (I-A*)-1 is calculated according to the direct consumption coefficient, so as to calculate the total output of various industries driven by the investment of power grid according to the formula $\Delta \mathrm{X}=(1-\mathrm{A}) . \Delta \mathrm{Y}$. According to the calculation, the investment of 11.557 billion yuan has led to an increase of 56.953 billion yuan in the total output of various industries.

\subsubsection{Calculation of GDP increment of power grid investment}

Firstly, the diagonal matrix A of value-added coefficient is calculated, and then the GDP increment ( $\triangle$ GDP) calculated by $\Delta \mathrm{GDP}=\mathrm{AZ} * \Delta \mathrm{X}$ is 16.773 billion yuan, that is, 11.557 billion yuan of investment can bring a total of 16.773 billion yuan of GDP increment to China in the next few years, and the investment multiplier is 1.45 . 


\subsection{Social benefit analysis of power grid investment}

\subsubsection{Measuring the contribution rate of employment}

According to the data of 42 industrial sectors in the input-output table, the direct employment contribution, indirect employment contribution and full employment contribution coefficient of power grid investment to each industry sector are calculated by employment contribution model.

\subsubsection{Measuring and calculating the number of employment promotion}

According to the quantitative model of economic impact of power grid investment, the investment amount of power grid infrastructure investment is decomposed, and the investment number of relevant departments is obtained. According to the average wage level of each industry sector in the statistical yearbook, the number of employments directly and indirectly driven by grid investment is calculated.

According to the calculation results, the investment in power grid infrastructure is 13.525 billion yuan, of which 11.557 billion yuan is the investment that plays a driving role in the economy, and 86790 people are employed. Among them, about 14043 jobs are directly added to the relevant industrial departments, and 72747 jobs are indirectly added to other industrial sectors. The employment effect of unit investment is 0.0152 person / 10000 -yuan, direct employment effect is 0.122 person / 10000-yuan, indirect employment effect is 0.0160 person / 10000 yuan. The pulling effect of power grid investment on employment is significant.

\section{Conclusion}

Based on the input-output method, the quantitative analysis of the economic and social benefits of power grid investment is carried out. After analysis, it is found that the power grid investment multiplier is 1.45 , that is, 1 unit of grid investment brings 1.45 units of GDP increment; at the same time, this paper analyses the pulling effect of investment on employment, if the employment effect of unit investment is 0.0152 person / 10000 yuan, the direct employment effect is 0.122 person / 10000 yuan, and the indirect employment effect is 0.0160 person / 10000 yuan. It can be seen that power grid investment has a significant role in promoting economic and social development, and also provides a quantitative reference for power grid investment decision-making and social responsibility performance.

\section{References}

1. Zhai Shujun, Sun Yue, Ji Liwei, Ma Zixiao. analysis of the economic impact of grid investment. China power enterprise management, 12:86-87 (2018)
2. Li Xiuting, Liu fan, $\mathrm{Wu} \mathrm{Di}$, Dong Jichang, Gao Peng. Macroeconomic effect analysis of China's real estate industry based on input-output model. System engineering theory and practice, 34:323-336 (2014)

3. Han Chun, Li Ying. Application and thinking of economic benefit evaluation mechanism of power grid project in investment decision. Enterprise management, 2:156-158 (2016)

4. Gong Jianfeng, Dang Dongsheng, Hu Zhibing. Research on the evaluation of power grid investment benefit under the open investment environment. Electromechanical information, 9:30-32 (2019) 